\title{
Suicide in the Early Stage of Schizophrenia
}

\section{Antonio Ventriglio ${ }^{1,2 *}$, Alessandro Gentile ${ }^{3}$, Iris Bonfitto ${ }^{1}$, Eleonora Stella', Massimo Mari², Luca Steardo ${ }^{4}$ and Antonello Bellomo ${ }^{1}$}

${ }^{1}$ Department of Clinical and Experimental Medicine, University of Foggia, Foggia, Italy, ${ }^{2}$ Department of Mental Health, Regione Marche, ASUR, Area Vasta 2, Jesi, Italy, ${ }^{3}$ Department of Mental Health, Regione Veneto, ULSS 13, Mirano, Italy,

${ }^{4}$ Department of Psychiatry, University of Naples SUN, Naples, Italy

Suicide is a relevant leading cause of death among patients affected by schizophrenia. Even if suicidal ideation may be present in different stages of disease, some differences have been described between the risk of suicide in patients experiencing first episode of psychosis and those with long-term schizophrenia. It is particularly higher during the first year of illness and reaches a steady decline over the following years. Suicidal ideation and attempts may also be common among subjects with subthreshold psychotic experiences. Factors associated with the risk of suicide in the early phase of schizophrenia are previous suicidal attempts and social aspects: the lack of social support and stable relationships, social drift after the first episode, and social impairment. Also, several psychotic symptoms (suspiciousness, paranoid delusions, mental disintegration and agitation, negative symptoms, depression and hopelessness, and command hallucinations) and substance abuse are associated with higher risk of suicide. It has been described that perfectionism and good levels of insight among individuals who have recently developed psychotic symptoms are significantly associated with higher numbers of suicidal attempts. Moreover, recent evidences show that prefrontal cortex-based circuit dysfunction may be related to suicide in the early stage of schizophrenia. This narrative review summarizes available evidences on suicide in the early stage of schizophrenia and deals with issues to be further studied and discussed.

Keywords: suicide, suicidal attempts, first episode of psychosis, schizophrenia

\section{INTRODUCTION}

The risk of suicide can be valued in a multistage continuum, which includes suicidal ideation (ideation, intent, and plans), as a critical initial step, attempted, and completed suicide. The long-term suicide risk in subjects without mental disorders is $0.3 \%$, whereas the risk measured among mentally ill patients ranges from $3.4 \%$ for people affected by one mental disorder to $6.2 \%$ for people reporting more than one psychiatric disorder: each additional psychiatric diagnosis seems to contribute significantly to increase risk of suicide (1). Suicidal ideation, obviously, is a predictor of suicide and the basis of suicide prevention in schizophrenia (2). Also, suicide is a relevant leading cause of death among patients affected by schizophrenia spectrum disorders, and the rate of attempted suicide in psychotic patients ranges from 10 to $50 \%(3,4)$. Individuals affected by schizophrenia $(40-79 \%)$ have had suicidal ideation at least one time during the course of illness $(5,6)$. Also, in schizophrenia, the estimated suicide rate is $579 / 100,000$ person years and the lifetime risk of suicidal death is $5.6 \%$ $(7,8)$. Anyway, rates of completed and attempted suicides among schizophrenia patients are lower 
than those reported for patients affected by other psychiatric conditions: 0.24 and 0.74 per 100 person years, respectively (9). In particular, the suicide-related mortality is higher among subjects recently diagnosed with schizophrenia ( $\leq 5$ years from diagnosis) (9). In fact, the suicide risk is twofold higher at the onset of psychotic illness than in the later course $(8,10,11)$. The first episode of psychosis (FEP) can be divided in four phases: (a) prodromic phase or emerging psychosis, (b) untreated psychosis (UP) (the duration of untreated psychosis is labeled as DUP), (c) acute psychosis and its treatment, and (d) post-psychotic recovery. Each phase is characterized by different risk of suicide as summarized in the Table 1. In the first phase (that may be called "at-risk mental state" or "prodromic"), suicidal behaviors may be due to the distress caused by unfamiliar emerging pre-psychotic experiences. The delay in accessing the mental health-care system and starting treatment (called DUP) may greatly contribute to increase suicide risk among schizophrenia patients at FEP (12). During the acute phase of schizophrenia, psychotic experiences (distressing delusions, command hallucinations, or passivity phenomena) and feelings, such as fear, stigma, and loss (in patients with some degree of insight), are relevant factors for suicide. Risk of suicide during the following phase of post-psychotic recovery may be related to the loss of role and function mostly due to neurocognitive sequelae (13).

\section{METHOD}

This narrative review provides an overview on the links between schizophrenia, FEP, and suicide. We selected and commented significant articles published on the topic during the last decades (from 1997 to 2016) searching through PubMed, Cochrane Library, and Web of Science/Web and Google Scholar. Key words

TABLE 1 | Risk of suicide during the first psychosis episode (FEP) phases.

\begin{tabular}{|c|c|c|}
\hline Phase & Incidence/epidemiology & Possible risk factors \\
\hline $\begin{array}{l}\text { Prodromic } \\
\text { phase or } \\
\text { emerging } \\
\text { psychosis }\end{array}$ & $\begin{array}{l}\text { About } 90 \% \text { of the young } \\
\text { people meeting criteria for } \\
\text { an at-risk mental state report } \\
\text { suicidal ideation ( } 91 \text { ) }\end{array}$ & $\begin{array}{l}\text { Distress caused by } \\
\text { unfamiliar emerging pre- } \\
\text { psychotic experiences }\end{array}$ \\
\hline $\begin{array}{l}\text { Untreated } \\
\text { psychosis } \\
\text { (UP-phase) } \\
\text { and duration } \\
\text { of untreated } \\
\text { psychosis } \\
\text { (DUP) }\end{array}$ & $\begin{array}{l}\text { Most of patients report } \\
\text { suicidal risk during this } \\
\text { phase, and } 25 \% \text { have already } \\
\text { attempted suicide before } \\
\text { seeing a psychiatrist. Rate of } \\
\text { completed suicides during the } \\
\text { UP is very high (92) }\end{array}$ & $\begin{array}{l}\text { The average delay in } \\
\text { accessing health-care } \\
\text { system during this phase is } \\
1 \text { year. Suicidality is higher } \\
\text { when DUP is longer }\end{array}$ \\
\hline $\begin{array}{l}\text { Acute } \\
\text { psychosis and } \\
\text { its treatment } \\
\text { (phase) }\end{array}$ & $\begin{array}{l}11 \% \text { of suicide attempts in } \\
\text { the FEP are associated with } \\
\text { hallucinations, fear, shame, } \\
\text { stigma, guilt, loss, rejection, } \\
\text { and despair (76) }\end{array}$ & $\begin{array}{l}\text { Patient's hallucinations, fear, } \\
\text { shame, stigma, guilt, loss, } \\
\text { rejection, and despair }\end{array}$ \\
\hline $\begin{array}{l}\text { Post-psychotic } \\
\text { recovery } \\
\text { (phase) }\end{array}$ & $\begin{array}{l}\text { After an acute episode, } 15 \% \\
\text { of the patients experience high } \\
\text { suicidality for the following } \\
18 \text { months (93-96) }\end{array}$ & $\begin{array}{l}\text { Even if the symptoms of } \\
\text { psychosis may remit in } \\
\text { this phase, neurocognitive } \\
\text { deficits may have an impact } \\
\text { on studying, working, and } \\
\text { recreational activities }\end{array}$ \\
\hline
\end{tabular}

employed for research were "First Psychotic Episode and Suicide," "Schizophrenia and Suicide," "FEP and Suicide," "FEP," "Suicide," "Schizophrenia self-injury," and "Schizophrenia and self-harm."

\section{INCIDENCE OF SUICIDE IN FEP}

A British 10-year follow-up study showed that subjects affected by FEP have died from unnatural causes more than general population (OR: 13). Suicide was recognized to be the cause of these deaths, and most of the suicides occurred in the first 2 years (14). According to the available evidences on rates of suicide in first-admission psychotic patients, $23 \%$ of these have already attempted suicide, and 15\% attempted it before the hospitalization (15). Recently, some authors aimed to test the progress in the field of suicide prevention and described the change in a 20 -year period of suicide risk among FEP schizophrenia patients belonging to the same catchment area. It was found that suicide risk decreased over the two decades with a reduction of suicide rate from 11.0 to $2.4 \%(4,11)$. These data may suggest that early intervention and therapy improve the suicidality among FEP patients, even if they may attempt suicide before their contact with any mental health service: in fact, mortality rates may be underestimated because of complete suicides committed before seeking professional help (8). In addition, the prevalence of deliberate self-harm (DSH) behaviors before psychosis is about $18.4 \%$ (16).

\section{SUBTHRESHOLD PSYCHOTIC EXPERIENCES AND SUICIDE IN SCHIZOPHRENIA}

In the last decades, the research highlighted the importance of early intervention of FEP in order to reduce the DUP. Longer DUP, in fact, is associated with poor outcome in schizophrenia with higher prevalence of suicidal behaviors (17). A Norwegian study showed that, in the early phases of FEP, 38.8\% of patients reported suicidal ideation and $25.9 \%$ attempted suicide before any treatment (17).

Authors from the Bonn School suggested the classification of "basic symptoms" of psychosis, which are subtle, subclinical, and detectable at an early stage such as distressing selfexperienced disturbances in perception, thinking, memory, motility, mood, sense of awareness, and mastering $(18,19)$. Authors underline the importance of detecting these symptoms in the early stage of psychosis to reduce the period of untreated illness (DUI).

A new psychopathological framework called attenuated psychosis (APS) disorder concerning subthreshold psychotic symptoms in youths was included in the Section 3 of the Diagnostic and Statistical Manual of Mental Disorders, 5th Edition, as a new putative disorder. The criteria specify that symptoms of APS are sufficiently distressing to call for clinical attention and very helpful to identify young people at risk for psychosis.

The early stages of psychosis were also labeled as "ultra high risk (UHR)," "at risk mental state (ARMS)," and "clinical high risk (CHR)." It is well known that self-harm behaviors and suicidality 
are highly prevalent in the UHR population, with rates similar to those observed in samples diagnosed with psychotic disorders (20). In addition, about $50 \%$ of young people recognized to be CHR for psychosis have reported current suicidal thoughts (21, 22 ). The prevalence of suicidal ideation among these samples is $42.9 \%$, and there may also be less severe parasuicidal ideation (22).

A meta-analysis of factors associated with DSH shows that the pooled proportion of patients who reported DSH before any treatment for FEP, during the period of UP, and during the period of clinical follow-up between 1 and 7 years from the clinical diagnosis, was, respectively, 18.4, 9.8, and 11.4\% (23).

Psychotic-like experiences (PLEs) are common in the general population and may be associated with poor social outcomes, even if there is no diagnosed psychotic disorder (24). Also, they are important but under-recognized markers of risk for severe psychopathology, including multimorbidity, poor functioning, and suicidal behaviors in young people attending the mental health-care services: in particular, individuals with subthreshold psychotic experiences are at increased risk for suicidal thoughts and behavior, similar to those with schizophrenia and other psychotic disorders, but it is unclear whether the level of risk varies with different types of PLEs (25). Moreover, self-reported auditory hallucinations are associated with twofold risk of suicidal ideation and suicidal plans and fourfold risk of suicide attempts in a non-clinical sample of young adults compared with the general population (26). Hypomania, thought control, paranoia, strange experience, and auditory hallucination in subject without definite psychosis were significantly associated with higher suicidal ideation and suicide attempt (ORs ranging from 3.13; 95\% CI $1.99-4.93$ to 4.03 ; 95\% CI 1.56-10.42) (27). Furthermore, recent studies demonstrated that only a lifetime history of perceptual abnormalities and persecutory ideation are associated with a higher risk of lifetime suicidality, instead, bizarre experiences were not associated with any suicide variable (28). In conclusion, allcause mortality is associated with lifetime psychotic experiences among schizophrenia patients over a 24- to 27-year follow-up period (after adjustment for sociodemographic characteristics and psychiatric diagnoses), and suicide seems to report a particularly high hazard ratio $(9.16,95 \%$ CI 3.19-26.29) (24).

\section{RISK FACTORS}

Several studies have been carried out on predictors of suicide in patients with schizophrenia in order to improve early detection of suicide risk and to provide suggestions for prevention (11).

\section{Age of Onset}

The relationship between suicide risk and age of onset of psychotic symptoms is complex. In a recent study conducted in a psychiatric unit for adolescents, most of teenagers who attempted suicide were diagnosed with schizophrenia spectrum disorder (29). Some studies have reported a higher risk of suicide in patients with earlier age of psychotic onset (30-32), whereas some other authors have found a relationship with later age of onset of psychosis (33-36): in all studies, age of onset is considered the only independent risk factor for suicide, with risk of suicide increasing by $1.1 \%$ per year $(4,33,35,36)$. Individuals who experience a later onset of psychosis may find it more difficult to accept since psychosis may impair their previous functioning, plans, and careers (4). Also, patients with a later age of onset in Singapore reported lower risk of suicide probably due to the fact that young people mostly live with parents throughout the years of schooling, and the family environment can be a protective factor against the risk of suicide (34). In addition, it is of interest that several other studies failed in finding any relationship between suicide risk and age of onset of psychotic symptoms $(37,38)$.

\section{Duration of Untreated Psychosis}

As stated above, longer DUP is one of the most commonly reported risk factors of poor outcome and suicide among schizophrenia patients (34). Melle et al. (12) showed that patients coming from a community without an early detection program of FEP had a higher risk of suicide if compared with those coming from "early detection communities" and concluded that early detection reduces the DUP and the rate of suicidal behaviors. They also suggested that early engagement of patients in a treatment program seems to have an independent effect on suicidality beyond any DUP (12). Clarke et al. (39) confirmed that individuals with a longer DUP may have a poorer outcome of illness that is associated with higher suicidality. Moreover, in a recent observational study based on a 10 -year period of observation, the association between time for remission from psychosis and mortality was studied and found to be statistically significant when adjusted for age at baseline and sex: authors point out that mortality is not only related to DUP but also to other demographic (e.g., sex and age), personal, and outcome factors (including time for remission), and mortality for "unnatural death" may include not only suicides but also accidents (40).

\section{Gender}

Contradictory gender patterns in suicidal behaviors among patients with FEP have been found. Some of these showed no relation with suicide risk, suggesting that the severity of a clinical condition could "override" gender differences in suicidal behaviors $(4,22,34)$. In some studies, males seem to be more suicidal than females (41-43), whereas some other reports show that female patients at FEP may show higher risk of suicide and suicidal behaviors $(12,30,32)$.

\section{Living Situation}

Studies show that only $20 \%$ of the patients who attempted suicide report a comfortable living situation; in most of the cases, there may be a concern regarding loneliness: that may suggest that living with others may be a protecting factor (4). In addition, some authors found an increased risk for suicide in patients who experienced the fear of losing their partner or social position (44). In fact, it is clinically relevant to focus psychotherapeutic interventions on the feeling of loss. It is of interest that the risk of unnatural-cause mortality is reduced by $90 \%$ when there is a family involvement at intake or first contact with mental health-care services (14). Further researches are also needed because family involvement and family cohesion are relevant factors that impacts on outcome of illness as well as socioeconomic status, level of education, etc. (14). 
It would also be very helpful to integrate and include families and caregivers in the early intervention programs in order to improve the outcome of FEP (40).

\section{Cognition and Education}

Several evidences report that higher education or higher cognitive functioning is associated with an increased risk of suicide in $\operatorname{FEP}(2,4,36,45,46)$. In particular, some of these studies described the relationship between neurocognitive variables and suicidality in patients with schizophrenia spectrum disorders. Nangle et al. have tested suicide attempters and non-attempters with an extensive neuropsychological battery examining premorbid and current general cognitive functioning, episodic memory, and executive functioning. They found that attempters have higher cognitive functioning than non-attempters. Specifically, higher levels of executive functions may influence the ability to plan suicidal behaviors (31). This is in agreement with previous researches showing that higher cognitive functions, in particular, attention and psychomotor speed, verbal fluency, verbal memory, working memory, and executive function, are associated with greater suicidality (47). Nevertheless, recently Barrett et al. have shown that among patients with schizophrenia spectrum disorders, there are no significant differences in neurocognitive functioning between suicide attempters and non-attempters (17). Even if neural dysfunctions responsible for suicide risk are still obscure, some authors have proposed that the prefrontal cortex (PFC) is involved in suicide based on neuroimaging and post-mortem studies. In particular, PFC activity during the goal representation (an important competency of cognitive control) seems to be related to long-term suicide risk in recent-onset schizophrenia, and suicidal behaviors may derive from impairments in premotor cortex support of action planning as an expression of control (48).

Moreover, Björkenstam et al. found a higher risk of suicide among patients who had completed compulsory school. Some other evidences showed that poorer school performance seems to increase the risk of suicide in the general population $(49,50)$. This may suggest that patients with higher education may feel more stigmatized and shameful when developing a mental disorder (44) and that this may lead to higher risk of suicide (50).

\section{Psychotic Symptoms in FEP and Suicide}

It has been inconsistently shown that negative symptoms may increase suicidal experience in CHR for psychosis individuals $(4,5,22,51)$. Some other authors point out that patients with prominent negative symptoms, in particular, deficits in emotion expressivity, may have significantly impaired ability to experience emotional distress caused by the illness: this may probably reduce the likelihood of developing a sense of hopelessness and suicidal ideation (2). Also, negative symptoms commonly overlap with depressive symptoms, and it is clinically relevant to distinguish the relationship between suicidal ideation and negative symptoms and/or depression among FEP patients. Gill et al. found that negative symptoms remained significantly correlated with severity and intensity of recent suicidal ideation even if adjusted for depression scores (22).
Disorganized symptoms seem to report a poor association with a higher risk of suicide (4). Finally, there is no relevant evidence on the impact of positive symptoms of psychosis and excitement on the risk of suicide $(4,22,37,38)$ even if some studies describe an association between command hallucinations and committed suicides $(34,52)$. In addition, some authors found that individuals with suicidal ideation during the prodromal phase of schizophrenia report higher scores of negative and positive symptoms than individuals without prodromal suicidal ideation $(22,53)$.

\section{Affective Symptoms in FEP and Suicide}

Depressive symptoms in the prodromal phase of schizophrenia were frequently associated with suicidality during the following 12 months of outcome (54). In particular, depressive symptoms are associated with lifetime as well as current risk for suicidal behaviors $(32,55)$ with higher rates of depression after the first episode and any relapse of psychosis $(56,57)$.

Many authors point out that, in FEP patients, depression and suicidal behavior may be a reaction to the perceived persecutors and entrapment (58). Some other authors found that hopelessness was associated with suicidal ideation in FEP individuals and this symptom predicted suicidal ideation (2).

It has also been hypothesized that suicidality in FEP may be linked to patients' altered basic self-awareness or sense of self, called self-disorders: there is a clear association between current suicidality and self-disorders, which appears to be connected by depressive states (59). Previously, Skodlar et al. (6) and Skodlar and Parnas (60) suggested that the effect of self-disorders on FEP was connected to specific feelings of inferiority and loneliness, and these feelings were different from "usual" feelings of low self-esteem or loneliness, since they are characterized by being profoundly dissimilar to other people.

"Mood variability" may also be associated with levels of suicidal thoughts and behaviors among individuals at UHR of developing psychosis through the re-activation of latent suicidal cognitions. In fact, in 2012, Palmier-Claus et al. showed that the variability of negative and positive affect was predictive of the frequency of suicidal thoughts and behaviors, with more variable negative affect associated with severe suicidal ideation and related behaviors. In a later study, they also investigated variability and levels of depressive mood, anxiety, and guilty during the schizophrenia FEP and after this episode. The findings support the hypothesis that variability in depression may contribute to suicidal ideation and related behaviors (61).

Early intervention on depression in FEP is crucial to minimize suicidal ideation and attempts, particularly, in the first years of illness, which seem to be consistently characterized by high risk of suicide (2).

Finally, it has been shown that ARMS and FEP patients had significantly higher scores at the brief psychiatric rating scale-excited component (BPRS-EC) if compared with healthy controls: this may suggest an agitated-aggressive syndrome characterized by impulsivity and increased risk of aggression and suicidality (62). 


\section{Schizophrenia and Affective Disorders: The "Continuum" Model}

Suicide may significantly occur in the outcome of affective disorders and schizophrenia. Epidemiological data show that unipolar depression, bipolar disorders, and schizophrenia are associated with significant risk of suicide (63). This finding might be explained through the "continuum" model in which some characteristics, dimensions, or syndromes (including suicide) are included in different clinical conditions caused by the same underlying mechanism. In fact, several studies proposed a psychopathological continuum between schizophrenia and mood disorders (64). In particular, neurobiological data show a relevant overlap between bipolar disorders with psychotic features and schizophrenia. Also, in the early stage of both disorders, genetic vulnerability markers seem to be located on the same chromosomes (65). In addition, schizophrenia and affective disorders present similarities in neurodysfunctions and neuromorphometric characteristics $(66,67)$. According to this model, risk of suicide may be influenced by different dimensions, such as mood variability and psychoticism, along a spectrum of affective and psychotic disorders.

\section{History of Suicide Attempts}

History of suicide attempts suggests an increased risk of suicide since it is supposed to be a strong predictor of later attempted or completed suicides $(2,9,68)$.

Similarly, history of self-harm or violent crime is a relevant risk factor for subsequent suicide in patients with FEP: both include some degree of impulsivity, which is associated with an increased risk of suicide (69).

\section{Functioning}

It is notable that schizophrenia is associated with a significant impairment in occupational functioning that can start early in the prodromal phase of illness.

Also, individuals with recent suicide ideation have poorer functioning, in particular, they report role deficits and lower scores at global assessment of functioning (GAF) $(22,34,53)$.

It has been found that social drift is common in psychotic disorders and individuals with a FEP. They are more likely to be in the lower social classes if compared with the general population. Also, social drift was associated with depression, hopelessness, and suicidality at first presentation of illness. However, the relationship between social class and prognosis is complex: hopelessness may be developed in subjects who maintain their social class or achieve upward social mobility. In addition, individuals who achieve upward social mobility are more likely to be ambitious, hardworking, and motivated, and they may have greater difficulty in coping strategies when their life progression is stopped by a psychotic disorder (70).

\section{Insight}

Insight is defined as the awareness of suffering from a mental disorder and needing of treatments. Several studies showed that better insight is associated with suicidal ideation and attempted suicide in FEP patients (71-75), while others specify that insight may influence the risk of suicide if associated with depression and hopelessness $(30,47,76-79)$. Conversely, some authors remarked that interventions aimed to improve the insight may also improve the outcome of illness and secondary reduce the risk of attempting suicide (79). In fact, interestingly, it was found that insight at baseline increases the risk for suicide while a good level of insight at 1-year follow-up (due to psychoeducational interventions) decreases the same risk: this may indicate that early insight is qualitatively different from insight after 1 year of treatment. Early insight may imply a negative change in self-image (switching from a healthy person to an ill one) or the awareness of consequences related to a mental disorder and stigma (80). Insight is associated with better treatment adherence in the long term and has a positive impact on the outcome of illness and risk of suicide (81).

In conclusion, authors point out that some domains of insight may increase the risk of suicide such as awareness of mental illness, and also some other factors like being female, longer DUP, and comorbid depression may increase the association between suicide and insight levels.

\section{Trauma}

There are few studies on trauma in FEP and its negative impact on clinical outcome. It is well known that traumatic life events may lead to anxiety, depression, and psychotic symptoms and can contribute to the development of an at-risk state for psychosis (82).

Conus et al. described the prevalence of stressful events in 658 FEP outpatients and their associations with premorbid characteristics, baseline, and outcome differences among subjects who did and did not report past sexual and/or physical abuse (SPA). They found that $83 \%$ of these patients had been exposed to at least one stressful event during their lifetime and 34\% of them to physical and/or sexual abuse (especially females). SPA patients were more likely to report post-traumatic stress disorder (PTSD) and substance use disorder before the onset of the psychosis to have attempted suicide in the past and during the treatment (83).

The effects of trauma and comorbid PTSD may add further risk of suicide in FEP patients. Tarrier et al. (77) investigated all post-traumatic stress symptoms and the effect on suicidal behavior of trauma associated with the psychotic onset. Eighty percent of the patients felt traumatized, and 38\% reported criteria for PTSD. Suicidal ideation was reported by $40 \%$ of the sample, and $31 \%$ reported attempted suicides. Suicidal behavior rates were higher in those suffering from PTSD, even if not statistically significant and significantly associated with the experience of trauma occurred before the onset of psychosis (77).

These results suggest that treatment of early psychosis must consider childhood trauma and comorbid PTSD. Assessment for PTSD has also been suggested in the National Institute for Clinical Excellence (NICE) guidelines in 2014 since it is helpful for further interventions in FEP patients (84).

\section{Other Factors}

Other factors may also predict the risk of suicide, although the findings are still inconsistent. Patients who completed suicide within 2 years from FEP showed more passive coping strategies or 
high level of neuroticism (4). Also, perfectionist self-presentation was associated with suicide in a case report of a FEP patient (85).

Family history of a first-degree relative hospitalized for schizophrenia or bipolar disorder or substance use disorder or other mental disorders was supposed to be associated with risk of suicide in FEP patients (69). Illicit drug use was associated with a twofold to fourfold increased risk of all- and unnatural-cause mortality, respectively, while controlling for age and sex (40, 86). The relatively high prevalence of concurrent and lifetime substance abuse in the FEP population may increase the rate of suicidal and aggressive behaviors (87).

Medication history is also to be considered among factors influencing suicide risk among schizophrenia patients. Even if evidences about the efficacy of antipsychotics on suicide and FEP are few, there is an agreement on clozapine and its superiority in treating resistant psychotic illness: in fact, clozapine is associated with a significant 3.3-fold lower overall suicidal risk compared with other antipsychotic treatments (63). Also, in December 2002, the Food and Drug Administration (FDA) approved indication for clozapine to reduce the risk of recurrent suicidal behavior in patients with schizophrenia or schizoaffective disorder (63).

\section{LIMITATIONS}

Limitations of this review may include the non-systematic approach in selecting the available literature: even if evidences reported were considered as relevant by the authors, any score assessment of the screened results, as well as any consensus statement among authors were employed. Subjectivity in selecting articles may be considered as a selection bias.

\section{CONCLUSION}

Suicide is one of the leading causes of premature death among individuals with schizophrenia and psychotic spectrum disorders, and the rate of attempted suicide in these patients is also high (88). This overview confirms that, in recent years, there has been a growing interest in the area of FEP. The most relevant risk factors for suicide in FEP are age of onset of psychotic symptoms, DUP, demographic characteristics, psychopathology, trauma, and insight (a list of risk and protective factors for suicide during FEP is shown in Table 2). Clinicians should assess risk of suicide

\section{REFERENCES}

1. Holmstrand C, Bogren M, Mattisson C, Bradvik L. Long-term suicide risk in no, one or more mental disorders: the Lundby Study 1947-1997. Acta Psychiatr Scand (2015) 132(6):459-69. doi:10.1111/acps.12506

2. Chung Chang W, Chen ESM, Hui CLM, Chan SKW, Lee EHM, Chen EYH. The relationships of suicidal ideation with symptoms, neurocognitive function, and psychological factors in patients with first-episode psychosis. Schizophr Res (2014) 157:12-8. doi:10.1016/j.schres.2014.06.009

3. Aleman A, Denys D. Mental health: a road map for suicide research and prevention. Nature (2014) 509:421-3. doi:10.1038/509421a

4. Castelein S, Liemburg EJ, de Lange JS, van Es FD, Visser E, Aleman A, et al. Suicide in recent onset psychosis revisited: significant reduction of suicide rate over the last two decades - a replication study of a Dutch
TABLE 2 | Risk and protective factors for suicide in FEP patients.

\begin{tabular}{ll}
\hline Risk factors & Protective factors \\
\hline $\begin{array}{l}\text { Acute psychotic symptoms/experiences } \\
\text { (e.g., hallucinations) }\end{array}$ & At least one close relationship \\
Mood variability and depression & Family support \\
Pre-existing or comorbid conditions, & Things to live for, e.g., plans for the \\
such as personality disorder and & future, children, pets, etc. \\
substance abuse/dependence & \\
The individual reaction to the impact of & Strong positive cultural/religious/ \\
the illness & personal values and anti-suicide \\
& attitudes \\
Traumatic life events & Social stability \\
PTSD features related to earlier trauma & Good service engagement and \\
or prior suicide attempt & optimism about recovery (hope) \\
Trauma associated with an unsatisfactory & Compliance to treatments \\
pathway to care & \\
Lower insight & Good insight \\
Longer DUP & Shorter DUP \\
\hline
\end{tabular}

PTSD, post-traumatic stress disorder; DUP, duration of untreated psychosis.

in the prodromal phase with subthreshold symptoms as well as during the FEP and along the entire course of the illness (89). A more exhaustive monitoring with systematic risk assessment should be conducted regularly during these phases to facilitate early detection of high-risk cases and to provide interventions for suicide prevention without any delay $(86,97)$. Antipsychotic treatment remains crucial for reducing suicide among FEP patients (90). Clozapine has shown superiority in reducing suicide risk among schizophrenia patients (63). Further studies are required to identify specific psychotherapeutic and psychosocial interventions that may offer more benefits for the prevention of suicidal behaviors in such patients. Specialized multidisciplinary early psychosis teams (psychiatrist, psychotherapist, social worker, etc.) could provide the interventions needed for supporting FEP patients and their family in a comprehensive manner.

\section{AUTHOR CONTRIBUTIONS}

$\mathrm{AV}, \mathrm{IB}, \mathrm{AG}$, and $\mathrm{ES}$ reviewed the literature and drafted the paper. $\mathrm{MM}, \mathrm{LS}$, and $\mathrm{AB}$ finalized the paper and provided suggestions to improve it.

incidence cohort. PLoS One (2015) 10(6):e0129263. doi:10.1371/journal. pone.0129263

5. Fenton WS, Mc Glashan TH, Victor BJ, Blyler CR. Symptoms, subtype, and suicidality in patients with schizophrenia spectrum disorders. Am J Psychiatry (1997) 154(2):199-204. doi:10.1176/ajp.154.2.199

6. Skodlar B, Tomori M, Parnas J. Subjective experience and suicidal ideation in schizophrenia. Compr Psychiatry (2008) 4:482-8. doi:10.1016/j. comppsych.2008.02.008

7. Hor K, Taylor M. Suicide and schizophrenia: a systematic review of rates and risk factors. J Psychopharmacol (2010) 24(11):81-90. doi:10.1177/ 1359786810385490

8. Nordentoft M, Madsen T, Fedyszyn I. Suicidal behavior and mortality in first-episode psychosis. J Nerv Ment Dis (2015) 203(5):387-92. doi:10.1097/ NMD.0000000000000296 
9. Fleischhacker WW, Kane JM, Geier J, Karayal O, Kolluri S, Eng SM, et al. Completed and attempted suicides among 18,154 subjects with schizophrenia included in a large simple trial. J Clin Psychiatry (2014) 75(3):e184-90. doi:10.4088/JCP.13m08563

10. Osby U, Correia N, Brandt L, Ekbom A, Sparén P. Mortality and causes of death in schizophrenia in Stockholm country, Sweden. Schizophr Res (2000) 45(1-2):21-8. doi:10.1016/S0920-9964(99)00191-7

11. Palmer BA, Pankratz VS, Bostwick JM. The lifetime risk of suicide in schizophrenia: a reexamination. Arch Gen Psychiatry (2005) 62:247-53. doi:10.1001/ archpsyc.62.3.247

12. Melle I, Johannesen JO, Friis S, Haahr U, Joa I, Larsen TK, et al. Early detection of the first episode of schizophrenia and suicidal behavior. Am J Psychiatry (2006) 163(5):800-4. doi:10.1176/ajp.2006.163.5.800

13. Power P, McGowan S. Suicide Risk Management in Early Intervention. (2011). Available from: http://www.mhpf.org.uk/resources/legislation-and-guidance/ suicide-risk-management-in-early-intervention

14. Dutta R, Murray RM, Hotopf M, Allardyce J, Jones PB, Boydell J. Reassessing the long-term risk of suicide after a first episode of psychosis. Arch Gen Psychiatry (2010) 67:1230-7. doi:10.1001/archgenpsychiatry.2010.157

15. Cohen S, Lavelle J, Rich CL, Bromet E. Rates and correlates of suicide attempts in first-admission psychotic patients. Acta Psychiatr Scand (1994) 90(3):167-71. doi:10.1111/j.1600-0447.1994.tb01573.x

16. Perez J. Review: about one in five people with first-episode psychosis have a history of deliberate self-harm. Evid Based Ment Health (2013) 16(4):113. doi:10.1136/eb-2013-101465

17. Barrett EA, Sundet K, Simonsen C, Agartz I, Lorentzen S, Mehlum L, et al. Neurocognitive functioning and suicidality in schizophrenia spectrum disorders.ComprPsychiatry (2011) 52:156-63.doi:10.1016/j.comppsych.2010.06.001

18. Gross G. The 'basic' symptoms of schizophrenia. Br J Psychiatry (1989) 7:21-5.

19. Comparelli A, De Carolis A, Emili E, Rigucci S, Falcone I, Corigliano V, et al. Basic symptoms and psychotic symptoms: their relationships in the at risk mental states, first episode and multi-episode schizophrenia. Compr Psychiatry (2014) 55(4):785-91. doi:10.1016/j.comppsych.2014.01.006

20. Taylor PJ, Hutton P, Wood L. Are people at risk of psychosis also at risk of suicide and self-harm? A systematic review and meta-analysis. Psychol Med (2015) 45(5):911-26. doi:10.1017/S0033291714002074

21. De Vylder JE, Oh A, Ben-David S, Azimov N, Harkavy-Friedman J, Corcoran CM. Obsessive compulsive symptoms in individuals at clinical risk for psychosis: association with depressive symptoms and suicidal ideation. Schizophr Res (2012) 140(1-3):110-3. doi:10.1016/j.schres.2012.07.009

22. Gill KE, Quintero JM, Poe SL, Moreira AD, Brucato G, Corcoran CM, et al. Assessing suicidal ideation in individuals at clinical high risk for psychosis. Schizophr Res (2015) 165(2-3):152-6. doi:10.1016/j.schres.2015.04.022

23. Challis S, Nielssen O, Harris A, Large M. Systematic meta-analysis of the risk factors for deliberate self-harm before and after treatment for first-episode psychosis. Acta Psychiatr Scand (2013) 127:442-54. doi:10.1111/acps.12074

24. Sharifi V, Eaton WW, Wu LT, Roth KB, Burchett BM, Mojtabai R. Psychotic experiences and risk of death in the general population: 24-27 year follow-up of the epidemiologic catchment area study. Br J Psychiatry (2015) 207:1-7. doi:10.1192/bjp.bp.113.143198

25. Kelleher I, Corcoran P, Keeley H, Wigman JT, Devlin N, Ramsay H, et al. Psychotic symptoms and population risk for suicide attempt: a prospective cohort study. JAMA Psychiatry (2013) 70(9):940-8. doi:10.1001/ jamapsychiatry.2013.140

26. De Vylder JE, Hilimire MR. Suicide risk, stress sensitivity, and self-esteem among young adults reporting auditory hallucinations. Health Soc Work (2015) 40(3):175-81. doi:10.1093/hsw/hlv037

27. Koyanagi A, Stickley A, Haro JM. Subclinical psychosis and suicidal behavior in England: findings from the 2007 adult psychiatric morbidity survey. Schizophr Res (2015) 168(1-2):62-7. doi:10.1016/j.schres.2015.07.041

28. Capra C, Kavanagh DJ, Hides L, Scott JG. Subtypes of psychotic-like experiences are differentially associated with suicidal ideation, plans and attempts in young adults. Psychiatry Res (2015) 228(3):894-8. doi:10.1016/j. psychres.2015.05.002

29. Krajewska K, Gawlik-Kotelnicka O, Gmitrowicz A. The relation of selected psychiatric disorders to occurrence of suicide attempts among teenage psychiatrically hospitalized patients. Pol Merkur Lekarski (2015) 38(228):329-31.
30. Bertelsen M, Jeppesen P, Petersen L, Thorup A, Ohlenschlaeger J, le Quach P, et al. Suicidal behaviour and mortality in first-episode psychosis: the OPUS trial. Br J Psychiatry Suppl (2007) 51:s140-6. doi:10.1192/bjp.191.51.s140

31. Nangle JM, Clarke S, Morris DW, Schwaiger S, McGhee KA, Kenny N, et al. Neurocognition and suicidal behaviour in an Irish population with major psychotic disorders. Schizophr Res (2006) 85:196-200. doi:10.1016/j. schres.2006.03.035

32. Austad G, Joa I, Johannessen JO, Larsen TK. Gender differences in suicidal behaviour in patients with first-episode psychosis. Early Interv Psychiatry (2015) 9(4):300-7. doi:10.1111/eip.12113

33. Kuo CJ, Tsai SY, Lo CH, Wang YP, Chen CC. Risk factors for completed suicide in schizophrenia. J Clin Psychiatry (2005) 66:579-85. doi:10.4088/JCP. v66n0506

34. Mitter N, Subramaniam M, Abdin E, Poon LY, Verma S. Predictors of suicide in Asian patients with first episode psychosis. Schizophr Res (2013) 151:274-8. doi:10.1016/j.schres.2013.10.006

35. Pompili M, Lester D, Grispini A, Innamorati M, Calandro F, Iliceto P, et al. Completed suicide in schizophrenia: evidence from a case-control study. Psychiatry Res (2009) 167:251-7. doi:10.1016/j.psychres.2008.03.018

36. Reutfors J, Brandt L, Jonsson EG, Ekbom A, Sparen P, Osby U. Risk factors for suicide in schizophrenia: findings from a Swedish population-based case-control study. Schizophr Res (2009) 108:231-7. doi:10.1016/j. schres.2008.12.023

37. Pratt D, Gooding P, Johnson J, Taylor P, Tarrier N. Suicide schemas in non-affective psychosis: an empirical investigation. Behav Res Ther (2010) 48:1211-20. doi:10.1016/j.brat.2010.08.005

38. Fedyszyn IE, Robinson J, Harris MG, Paxton SJ, Francey S. Predictors of suicide-related behaviors during treatment following a first episode of psychosis: the contribution of baseline, past, and recent factors. Schizophr Res (2012) 140:17-24. doi:10.1016/j.schres.2012.06.022

39. Clarke M, Whitty P, Browne S, Mc Tigue O, Kinsella A, Waddington JL, et al. Suicidality in first episode psychosis. Schizophr Res (2006) 86(1-3):221-5. doi:10.1016/j.schres.2006.05.026

40. Revier CJ, Reininghaus U, Dutta R, Fearon P, Murray RM, Doody GA, et al. Ten-year outcomes of first-episode psychoses in the MRC AESOP-10 study. J Nerv Ment Dis (2015) 203(5):379-86. doi:10.1097/ NMD.0000000000000295

41. Healy D, Le Noury J, Harris M, Butt M, Linden S, Whitaker C, et al. Mortality in schizophrenia and related psychoses: data from two cohorts, 1875-1924 and 1994-2010. BMJ Open (2012) 2:10. doi:10.1136/bmjopen-2012-001810

42. Dutta R, Murray RM, Allardyce J, Jones PB, Boydell J. Early risk factors for suicide in an epidemiological first episode psychosis cohort. Schizophr Res (2011) 126:11-9. doi:10.1016/j.schres.2010.11.021

43. Lester D. Sex differences in completed suicide by schizophrenic patients: a meta-analysis. Suicide Life Threat Behav (2006) 36:50-6. doi:10.1521/ suli.2006.36.1.50

44. Agerbo E. High income, employment, postgraduate education, and marriage: a suicidal cocktail among psychiatric patients. Arch Gen Psychiatry (2007) 64:1377-84. doi:10.1001/archpsyc.64.12.1377

45. Drake RE, Gates C, Whitaker A, Cotton PG. Suicide among schizophrenics: a review. Compr Psychiatry (1985) 26:90-100. doi:10.1016/0010-440X(85) 90053-7

46. Delaney C, McGrane J, Cummings E, Morris DW, Tropea D, Gill M, et al. Preserved cognitive function is associated with suicidal ideation and single suicide attempts in schizophrenia. Schizophr Res (2012) 140:232-6. doi:10.1016/j.schres.2012.06.017

47. Kim CH, Jayathilake K, Meltzer HY. Hopelessness, neurocognitive function, and insight in schizophrenia: relationship to suicidal behavior. Schizophr Res (2003) 60:71-80. doi:10.1016/S0920-9964(02)00310-9

48. Minzenberg MJ, Lesh TA, Niendam TA, Yoon JH, Rhoades RN, Carter CS. Frontal cortex control dysfunction related to long-term suicide risk in recent-onset schizophrenia. Schizophr Res (2014) 157:19-25. doi:10.1016/j. schres.2014.05.039

49. Alaraisanen A, Miettunen J, Lauronen E, Rasanen P, Isohanni M. Good school performance is a risk factor of suicide in psychoses: a 35-year follow up of the Northern Finland 1966 Birth Cohort. Acta Psychiatr Scand (2006) 114(5):357-62. doi:10.1111/j.1600-0447.2006.00800.x 
50. Björkenstam C, Weitoft GR, Hjern A, Nordstrom P, Hallqvist J, Ljung R. School grades, parental education and suicide - a national register-based cohort study. JEpidemiol Community Health (2011) 65(11):993-8. doi:10.1136/ jech.2010.117226

51. Mc Girr A, Tousignant M, Routhier D, Pouliot L, Chawky N, Margolese HC, et al. Risk factors for completed suicide in schizophrenia and other chronic psychotic disorders: a case-control study. Schizophr Res (2006) 84:132-43. doi:10.1016/j.schres.2006.02.025

52. Kjelby E, Sinkeviciute I, Gjestad R, Kroken RA, Løberg EM, Jørgensen HA, et al. Suicidality in schizophrenia spectrum disorders: the relationship to hallucinations and persecutory delusions. Eur Psychiatry (2015) 30(7):830-6. doi:10.1016/j.eurpsy.2015.07.003

53. Andriopoulos I, Ellul J, Skokou M, Beratis S. Suicidality in the "prodromal" phase of schizophrenia. Compr Psychiatr (2011) 52(5):479-85. doi:10.1016/j. comppsych.2010.10.011

54. Sanchez-Gistau V, Baeza I, Arango C, Gonzalez-Pinto A, de la Serna E, Parellada M, et al. The affective dimension of early-onset psychosis and its relationship with suicide. JChild Psychol Psychiatry (2015) 56(7):747-55. doi:10.1111/jcpp.12332

55. Barret EA, Mork E, Færden A, Nesvåg R, Agartz I, Andreassen OA, et al. The development of insight and its relationship with suicidality over one year follow-up in patients with first episode psychosis. Schizophr Res (2015) 162:97-102. doi:10.1016/j.schres.2015.01.004

56. Upthegrove R. Depression in schizophrenia and early psychosis: implications for assessment and treatment. Adv Psychiatr Treat (2009) 15:372-9. doi:10.1192/apt.bp.108.005629

57. Upthegrove R, Birchwood M, Ross K, Brunett K, McCollum R, Jones L. The evolution of depression and suicidality in first episode psychosis. Acta Psychiatr Scand (2010) 122:211-8. doi:10.1111/j.1600-0447.2009.01506.x

58. Upthegrove R, Ross K, Brunet K, McCollum R, Jones L. Depression in first episode psychosis: the role of subordination and shame. Psychiatry Res (2014) 217:177-84. doi:10.1016/j.psychres.2014.03.023

59. Hauga E, Melle I, Andreassen OA, Raballo A, Bratlien U, Øie M, et al. The association between anomalous self-experience and suicidality in first-episode schizophrenia seems mediated by depression. Compr Psychiatry (2012) 53:456-60. doi:10.1016/j.comppsych.2011.07.005

60. Skodlar B, Parnas J. Self-disorder and subjective dimensions of suicidality in schizophrenia. Compr Psychiatry (2010) 51(4):363-6. doi:10.1016/j. comppsych.2009.11.004

61. Palmier-Claus J, Shryane N, Taylor P, Lewis S, Drake R. Mood variability predicts the course of suicidal ideation in individuals with first and second episode psychosis. Psychiatry Res (2013) 206(2-3):240-5. doi:10.1016/j. psychres.2012.11.014

62. Huber CG, Smieskova R, Schroeder K, Studerus E, Harrisberger F, Aston J, et al. Evidence for an agitated-aggressive syndrome predating the onset of psychosis. Schizophr Res (2014) 157(1-3):26-32. doi:10.1016/j.schres.2014.06.014

63. Tondo L, Isacsson G, Baldessarini R. Suicidal behaviour in bipolar disorder: risk and prevention. CNS Drugs (2003) 17(7):491-511. doi:10.2165/00023210-200317070-00003

64. Craddock N, Owen MJ. The Kraepelinian dichotomy - going, going... but still not gone. Br J Psychiatry (2010) 196:92-5. doi:10.1192/bjp.bp.109.073429

65. Möller HJ. Bipolar disorder and schizophrenia: distinct illnesses or a continuum? J Clin Psychiatry (2003) 64(Suppl 6):23-7.

66. Cardno AG, Owen MJ. Genetic relationships between schizophrenia, bipolar disorder, and schizoaffective disorder. Schizophr Bull (2014) 40(3):504-15. doi:10.1093/schbul/sbu016

67. Mamah D, Alpert KI, Barch DM, Csernansky J, Wang L. Subcortical neuromorphometry in schizophrenia spectrum and bipolar disorders. Neuroimage Clin (2016) 11:276-86. doi:10.1016/j.nicl.2016.02.011

68. Sanchez-Gistau V, Baeza I, Arango C, González-Pinto A, de la Serna E, Parellada M, et al. Predictors of suicide attempt in early-onset, first-episode psychoses: a longitudinal 24-month follow-up study. J Clin Psychiatry (2013) 74(1):59-66.1. doi:10.4088/JCP.12m07632

69. Björkenstam C, Björkenstam E, Hjern A, Bodén R, Reutfors J. Suicide in first episode psychosis: a nationwide cohort study. Schizophr Res (2014) 157:1-7. doi:10.1016/j.schres.2014.05.010

70. O’Donoghue B, Lyne JP, Fanning F, Kinsella A, Lane A, Turner N, et al. Social class mobility in first episode psychosis and the association with depression, hopelessness and suicidality. Schizophr Res (2014) 157:8-11. doi:10.1016/j. schres.2014.05.022

71. Crumlish N, Whitty P, Kamali M, Clarke M, Browne S, McTigue O, et al. Early insight predicts depression and attempted suicide after 4 years in first-episode schizophrenia and schizophreniform disorder. Acta Psychiatr Scand (2005) 112(6):449-55. doi:10.1111/j.1600-0447.2005.00620.x

72. Robinson J, Cotton S, Conus P, Schimmelmann BG, McGorry P, Lambert M. Prevalence and predictors of suicide attempt in an incidence cohort of 661 young people with first-episode psychosis. Aust N Z J Psychiatry (2009) 43(2):149-57. doi:10.1080/00048670802607162

73. Barrett EA, Sundet K, Faerden A, Nesvåg R, Agartz I, Fosse R, et al. Suicidality before and in the early phases of first episode psychosis. Schizophr Res (2010) 119(1-3):11-7. doi:10.1016/j.schres.2010.03.022

74. Foley S, Jackson D, McWilliams S, Renwick L, Sutton M, Turner N, et al. Suicidality prior to presentation in first-episode psychosis. Early Interv Psychiatry (2008) 2(4):242-6. doi:10.1111/j.1751-7893.2008.00084.x

75. Amador XF, Friedman JH, Kasapis C, Yale SA, Flaum M, Gorman JM. Suicidal behavior in schizophrenia and its relationship to awareness of illness. Am J Psychiatry (1996) 153(9):1185-8. doi:10.1176/ajp.153.9.1185

76. Nordentoft M, Jeppesen P, Abel M, Kassow P, Petersen L, Thorup A, et al. OPUS study: suicidal behavior; suicidal ideation and hopelessness among patients with first-episode psychosis. One year follow-up of a randomized controlled trial. Br J Psychiatry (2002) 181(Suppl 43):S98-106. doi:10.1192/ bjp. $181.43 . s 98$

77. Tarrier N, Khan S, Joanne C, Picken A. The subjective consequences of suffering a first episode psychosis: trauma and suicide behavior. Soc Psychiatry Psychiatr Epidemiol (2007) 42:29-35. doi:10.1007/s00127-0060127-2

78. Bakst S, Rabinowitz J, Bromet EJ. Antecedents and patterns of suicide behavior in first-admission psychosis. Schizophr Bull (2010) 36(4):880-9. doi:10.1093/ schbul/sbp001

79. Bourgeois M, Swendsen J, Young F, Amador X, Pini S, Cassano GB, et al. Awareness of disorder and suicide risk in the treatment of schizophrenia: results of the international suicide prevention trial. Am J Psychiatry (2004) 161(8):1494-6. doi:10.1176/appi.ajp.161.8.1494

80. Lysaker PH, Vohs J, Hillis JD, Kukla M, Popolo R, Salvatore G, et al. Poor insight into schizophrenia: contributing factors, consequences and emerging treatment approaches. Expert Rev Neurother (2013) 13(7):785-93. doi:10.158 6/14737175.2013.811150

81. Lincoln TM, Lüllmann E, Rief W. Correlates and long-term consequences of poor insight in patients with schizophrenia. A systematic review. Schizophr Bull (2007) 33(6):1324-42. doi:10.1093/schbul/sbm002

82. Latatser T, van Os J, Drukker M, Henquet C, Feron F, Gunther N, et al. Childhood victimization and developmental expressions of non-clinical delusional ideation and hallucinatory experiences: victimisation and non-clinical psychotic experiences. Soc Psychiatry Psychiatr Epidemiol (2006) 41:423-8. doi:10.1007/s00127-006-0060-4

83. Conus P, Cotton S, Schimmelmann BG, McGorry PD, Lambert M. Pretreatment and outcome correlates of sexual and physical trauma in an epidemiological cohort of first-episode psychosis patients. Schizophr Bull (2010) 36(6):1105-14. doi:10.1093/schbul/sbp009

84. NICE Clinical Guideline. 178 Psychosis and Schizophrenia in Adults: Treatment and Management Issued. (2014). Available from: https://www.nice.org.uk/ guidance/cg178

85. Hassan S, Flett GL, Ganguli R, Hewitt PL. Perfectionistic self-presentation and suicide in a young woman with major depression and psychotic features. Case Rep Psychiatry (2014) 2014:901981. doi:10.1155/2014/901981

86. Chung Chang W, Chen ESM, Hui CLM, Chan SKW, Lee EHM, Chen EYH. Prevalence and risk factors for suicidal behavior in young people presenting with first-episode psychosis in Hong Kong: a 3-year follow-up study. Soc Psychiatry Psychiatr Epidemiol (2015) 50:219-26. doi:10.1007/ s00127-014-0946-5

87. Cantwell R, Brewin J, Glazebrook C, Dalkin T, Fox R, Medley I, et al. Prevalence of substance misuse in first-episode psychosis. Br J Psychiatry (1999) 174:150-3. doi:10.1192/bjp.174.2.150

88. PayneJ,MallaA,NormanR, WindellD,HonsBA,Brown N.Statusoffirst-episode psychosis patients presenting for routine care in a defined catchment area. Can J Psychiatry (2006) 51(1):42-7. doi:10.1177/070674370605100108 
89. Pompili M, Serafini G, Innamorati M, Lester D, Shrivastava A, Girardi P, et al. Suicide risk in first episode psychosis: a selective review of the current literature. Schizophr Res (2011) 129(1):1-11. doi:10.1016/j.schres.2011. 03.008

90. Birchwood M, Spencer E. Early intervention in psychotic relapse. Clin Psychol Rev (2001) 21:1211-26. doi:10.1016/S0272-7358(01)00105-2

91. Adlard S. An Analysis of Health Damaging Behaviours in Young People at High Risk of Psychosis [FRANZCP Dissertation]. Melbourne: The Royal College and New Zealand College of Psychiatrists (1997).

92. Addington J, Williams J, Young J, Addington D. Suicide behaviour in early psychosis. Acta Psychiatr Scand (2004) 109:116-20. doi:10.1046/j.0001-690X. 2003.00232.x

93. Hunt IM, Kapur NN, Webb RT, Robinson J, Burns JM, Shaw J, et al. Suicide in recently discharged psychiatric patients: a case-control study. Psychol Med (2009) 39(3):443-9. doi:10.1017/S0033291708003644

94. Heilä H, Heikkinen ME, Isometsä ET, Henriksson MM, Marttunen MJ, Lönnqvist JK. Life events and completed suicide in schizophrenia: a comparison of suicide victims with and without schizophrenia. Schizophr Bull (1999) 25:519-31. doi:10.1093/oxfordjournals.schbul.a033398

95. Power P, Bell R, Mills R, Herrmann-Doig T, Davern M, Henry L, et al. Suicide prevention in first episode psychosis: the development of a randomized controlled trial of cognitive therapy for acutely suicidal patients with early psychosis. Aust N Z J Psychiatry (2003) 37(4):414-20. doi:10.1046/j. 1440-1614.2003.01209.x

96. Rossau CD, Mortensen PB. Risk factors for suicide in patients with schizophrenia: nested case-control study. Br J Psychiatry (1997) 171:355-9. doi:10.1192/ bjp.171.4.355

97. Sveticic J, De Leo D. The hypothesis of a continuum in suicidality: a discussion on its validity and practical implications. Ment Illn (2012) 4:e15. doi:10.4081/ mi.2012.e15

Conflict of Interest Statement: The authors declare that the research was conducted in the absence of any commercial or financial relationships that could be construed as a potential conflict of interest.

Copyright (c) 2016 Ventriglio, Gentile, Bonfitto, Stella, Mari, Steardo and Bellomo. This is an open-access article distributed under the terms of the Creative Commons Attribution License (CC BY). The use, distribution or reproduction in other forums is permitted, provided the original author(s) or licensor are credited and that the original publication in this journal is cited, in accordance with accepted academic practice. No use, distribution or reproduction is permitted which does not comply with these terms. 